\title{
The heart of the white paper controversy
}

\author{
Will finance be found for continued expansion?
}

Doctors' clinical work makes them realists; every day they are forced to distinguish what is possible for a patient from what might seem desirable. So not surprisingly despite a long summer of debate and protest about the white paper on the future of the NHS ${ }^{\prime}$ the BMA is continuing discussions (p 982). It has no wish to see medicine enter the same sort of decline as that affecting education, with doctors becoming as disenchanted and demoralised as their contemporaries in the schools and universities. The year has been notable for the prominent use of the media by the government and the BMA. Yet despite occasional unhelpful cries of "victory" from the media there is still room for discussion, for the government is keenly aware that many voters do not believe the NHS is safe in its hands and is anxious to allay those doubts.

The debate will continue in parliament, and press interest will be maintained. But what will the discussions have to cover? It may be helpful briefly to review the events of the past couple of years. The white paper was the government's response to the NHS crisis of 1987-8, when health authorities ran out of money and thousands of hospital beds were closed, waiting lists lengthened, heart operations on children were repeatedly cancelled, and the whole nation, it seemed, agreed that something needed to be done.' The medical profession saw the problem as essentially one of underfunding; it based this assertion partly on comparisons with other western countries ("Britain spends a lot less on health and a lot more on defence than its neighbours") and partly on the reports of bodies such as the House of Commons Social Services Committee, which had calculated that "the NHS had been underfunded by around $£ 2000$ million in the 1980s."

The government's response took some time to emerge and was then in line with its political philosophy. It believes that public expenditure is inflationary and should be kept down; so it looked for ways of making the NHS more efficient by introducing competition, market forces, closer budgeting controls on general practitioners and hospitals, and encouragement to hospitals to "opt out."

These proposals, as set out in the white paper, relied heavily on theoretical solutions devised by economists and administrators. The response by the medical profession (not just the BMA, but the royal colleges and virtually every medical and nursing organisation) was critical and impatient. ${ }^{+5}$ These plans, said the doctors, might or might not prove feasible; but was it not an enormous gamble to attempt (yet again) to restructure the NHS without any sound empirical evidence that the new arrangements would be superior to the old ones? To most NHS professionals many of the white paper plans seemed irrelevant to their day to day struggles to keep the service to patients running. Furthermore, the proposed timetable was quite unrealistic. If the government wanted to try out some new schemes, let it set up pilot projects and evaluate them properly.

\section{New evidence}

Events have now, however, moved on. The months of political skirmishing have seen publication in the $B M \mathcal{F}$ and elsewhere of the views of a few managers and a few clinicians arguing that the plans could work and they would like the chance to put the ideas into action. ${ }^{6}$ Some of the white paper's ideas - including its management concepts, money following patients, and medical audit - have been generally accepted as sound. But evidence has also been published from a wide range of sources showing that introducing these plans will be both difficult and expensive. Probably the most important such report is the evaluation by the Central Consultants and Specialists Committee of the experience of the six hospitals chosen as experimental sites for the resource management initiative (p 984).

The report shows that the six hospitals approached the experiment in different ways, but eventually they agreed on the two essential elements - a management system in which clinicians took a leading part and a "credible information system geared to clinical needs." What also emerged from practical experience with the project was the need for trained staff - in particular, medical secretaries. If the system is to be introduced nationally then substantial improvement will be needed in the pay and career prospects of secretaries, and business managers and other administrative staff will have to be recruited. "The establishment of information systems," says the report, "is extremely time consuming and expensive and requires considerable support and input from experts. To rush the process or to seek to do it on the cheap would be a waste of time and money."

Another valuable study carried out earlier in the year by the National Association of Health Authorities looked at the experience of the many health districts that are already buying and selling clinical services and the problems they had encountered. ${ }^{7}$ One of these is the uncertainty of a system governed by market forces - an uncertainty to which markets 
tend to respond by forming cartels and monopolies. Another is that some districts have been tempted by financial pressures to give priority to private patients or other districts' contracts at the expense of local people. The report was also concerned about standards - the need for measures of patient satisfaction to be incorporated into the process. Its conclusion was that "The changes represent an attempt to introduce market incentives for improving performance... but the market must either be regulated to prevent politically unacceptable variation in access and standards and will therefore be unable to achieve what a natural market does or it must be freed from restraint still further."

Evidence has also emerged rebutting one of the main planks in the government's case - that the NHS must be inefficient because there are wide variations around the country in measures such as referral rates to hospitals by general practitioners, treatment rates, the number of days spent in hospital by patients having standard operations, and so on. Studies of other systems show, however, that similar variability is found no matter how health care is organised and financed; the variations are as substantial in the United States as in Britain. ${ }^{8}$

Giving doctors reliable, accurate information about the outcome of their patients' attendance at hospital clinics clinical effectiveness - seems, however, to reduce the range of variations in referral rates. Indeed, one of the most striking outcomes of the debate about the white paper has been a surge of interest among doctors in information systems and in audit, both clinical and administrative. Doctors have been talking about audit ever since the obstetricians pioneered its use with their confidential inquiries into maternal deaths; but in the past year or two the concept has been put into practice in scores of hospitals and general practices and the trend now has an irresistible momentum. (Early next year the $B M \mathcal{F}$ will start regular publication of a special section on audit including both review articles and accounts of individual projects.)

Audit requires accurate information; so, too, do screening and immunisation programmes. ${ }^{9}$ Another spin off from the summer's debates has been evidence that the targets set for general practitioners for take up of these programmes are often unrealistic. The registers maintained by family practitioner committees are so inaccurate and out of date that attempts to contact target groups by post may result in as many as half the letters failing to reach the people concerned. ${ }^{10}$ Some health districts have reliable, comprehensive computer systems; many do not. Most are now at least aware of the need to identify their shortcomings and deal with them.

Meanwhile the Secretary of State for Health, Mr Kenneth Clarke, is refusing to modify his timetable for introducing legislation and putting it into effect, and he still hopes to have hundreds of hospitals operating the new system in 1991. No one outside Whitehall seems to believe that this sort of progress is possible; even the American experts such as Professor Alain Enthoven, who provided the theoretical basis for a provider market, reckon that any hospital wanting to set up a computer based pricing and monitoring system should expect to take four years. ${ }^{11}$ So the likely outcome seems to be continuing uncertainty and experimentation into the mid to late $1990 \mathrm{~s}$, with an incalculable effect on staff morale and no indication when any savings may be expected to emerge from the confusion.

However much ministers may try to dismiss the issue, savings and finance remain at the heart of the matter. Already there are signs that health authorities are facing another winter of cutbacks and closures - mostly because the increased funding for the NHS in November has been swallowed up by pay rises well above the $5 \%$ calculation for inflation. The prices of many items such as drugs have also risen by more than $5 \%$. So in the now all too familiar ritual: beds are closed (77 at St Bartholomew's in London), new operating theatres will stand unused (Kettering), and a new cardiology unit cannot be used (Oxford). ${ }^{2}$ As we said in 1988, and has been said time and time again, the NHS needs more money (not much more but some more) and it needs the money urgently.

Of course the picture is not all black. In many parts of the country the NHS is still a success. On measures such as the numbers of patients treated for end stage renal failure it is continuing to expand its activities. Patients are benefiting from new expensive drugs - thrombolytics, growth hormone, erythropoietin, and zidovudine - though clinicians complain that not all those who need these drugs are getting them.' Growth of this kind is what the public expects as it reads in newspapers and sees on television accounts of the very real advances being made each year in the diagnosis and control of disease. That is why all Western countries are spending steadily more (in real terms) on health care.

So as the discussions between the BMA and the Department of Health continue this autumn they must not lose sight of the prime issue-despite the obscuring effects of a fog of management jargon and economic ideology that has been blown over the scene. The question to be answered-given the commitment by all political parties to a state funded health system - is whether governments in the 1990s will find the money needed for sustained real growth in health expenditure to take account of demographic change, technological advances, the need for rebuilding and refurbishing the nation's hospitals, and providing the prevention and community services the population wants. That is the question the white paper did not answer-but it remains the heart of the matter.

Deputy Editor, $B M \mathcal{F}$

TONY SMITH

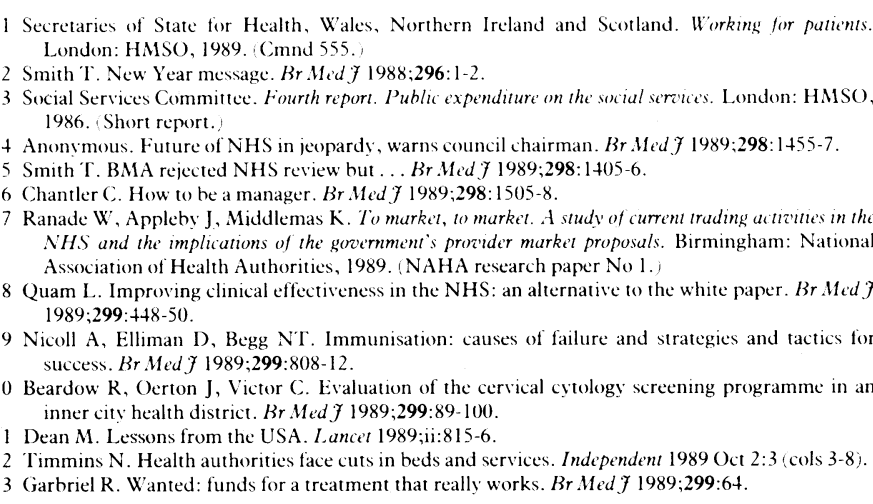

I Secretaries of State for Health, Wales, Northern Ireland and Scotland. Working for patient London: HMSO, 1989. Cmnd 55

Smith T. New Year message. Br. Hed 7 1988;296:1-2

Social Services Committce. Fourth report. Public expenditure on the social sereices. London: HMSO, 1986. Short report

Anonsmous. Future of NHS in jeopardy, warns council chairman. Br. Med f 1989:298: 1455-7. Smith T. BMA rejected NHS review but ... Br. Med f 1989;298: 1405-6.

6 Chantler C. How to be a manager. Br. Med J 1989;298:1505-8.

Ranade W, Applebs J, Middlemas K. To murket, to market. A studv of current trading actizities in the NHS and the implications of the government's provider market proposals. Birmingham: Nation Association of Health Authorities, 1989. NAHA research paper No I.

8 Quam L. Improving clinical effectiveness in the NHS: an alternative to the white paper. Br Medf $1989 \cdot 299 \cdot 4+4-50$.

Nicoll A, Elliman D, Begg NT. Immunisation: causes of filure and strategies and tactics lio success. Br Med f 1989;299:808-12.

10 Beardow R, Oerton J, Victor C. Evaluation of the cervical cytology screening programme in an inner city health district. Br.Med $\mathcal{F}$ 1989;299:89-100.

Dean M. Lessons from the USA. Lancet 1989;ii:815-6.

12 Timmins N. Health authorities face cuts in beds and services. Independent 1989 Oct 2:3 (cols 3-8) 3 Garbriel R. Wanted: funds for a treatment that really works. Br.Med F 1989;299:64.

\section{Ethnic population and general practitioners' workload}

\section{Variations in disease and consultation rates}

Britain is a multiethnic society, and has been so for two millenia. This multiplicity has led to many of the strengths of our society, both social and medical. Yet of the many factors that influence a general practitioner's workload' the ethnic origin of patients has received little attention..$^{2-5}$ First and second generation immigrants may make up a substantial fraction of the population of many inner city general practices.

Studies of the effect of this ethnic mix must be objective so as not to be construed as having political or racial overtones. Two papers in this week's $B M \mathcal{F}$ (pp 953 and 958) fulfil these requirements and add to our knowledge. They mirror many 